\title{
FORAMEN IN THE HUMERUS CAUSED BY THE MEDIAN NERVE
}

\author{
Robert RoAf, OsWestry, ENGLAND
}

In January 1954 a boy of sixteen consulted me complaining of pain and weakness in his left hand. A dislocation of the elbow with displacement of the medial epicondyle, sustained in 1949, had been treated at another hospital, whose notes made no mention of any nerve lesion; the original radiographs were not available.

Examination revealed a complete median nerve lesion. Radiographs showed some alteration in the shape of the lower end of the humerus, particularly the trochlea, and a foramen on the medial border of the bone just over an inch above the lower end (Fig. 1).

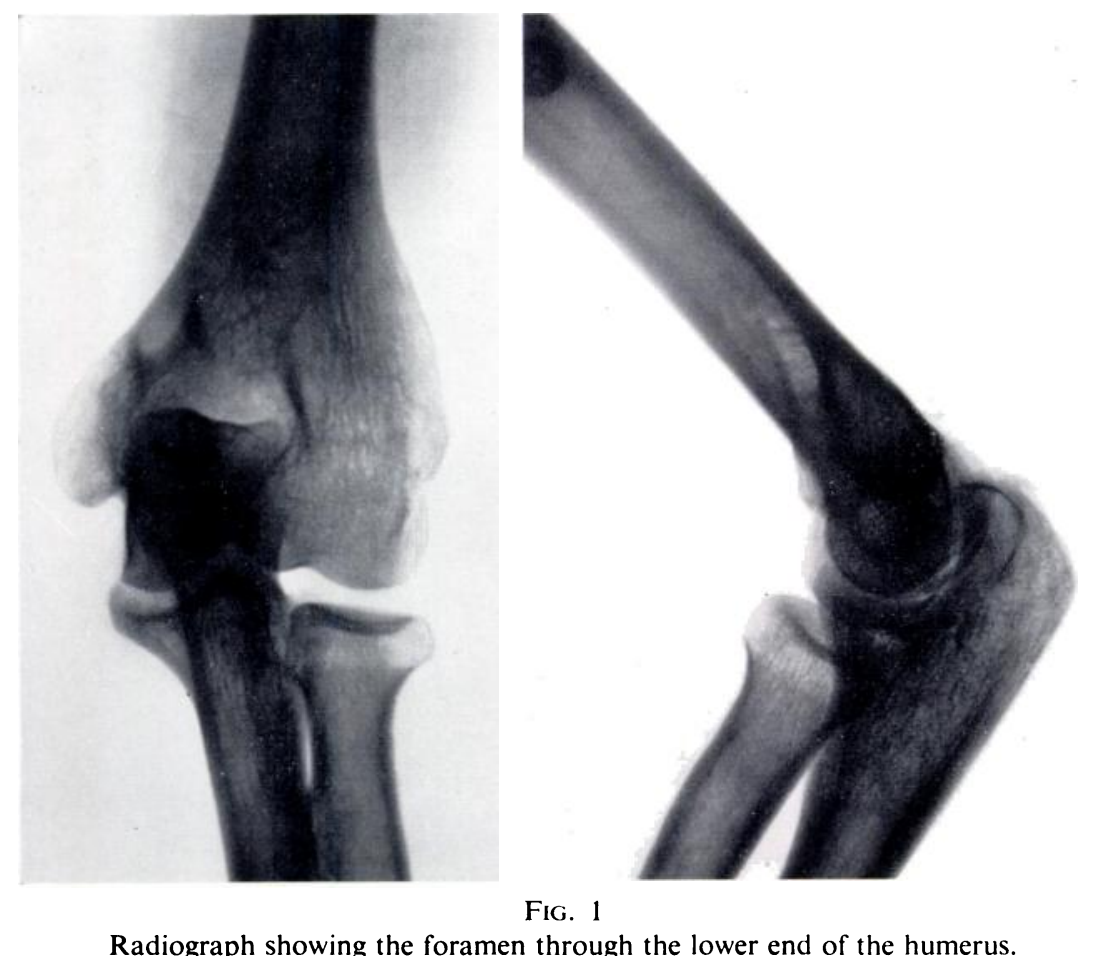

As it was uncertain how long the median nerve lesion had been present, exploration was offered. At operation the nerve was found to be normal as far as the foramen in the bone. Through this it passed from front to back, continuing distally to end in a large neuroma adherent to the back of the capsule of the elbow. The part of the nerve between the foramen and the neuroma looked and felt normal. The distal end of the median nerve was now exposed in the forearm and was traced proximally, being found to end in a neuroma stuck to the front of the elbow joint. The nerve ends were freed and the neuromata were excised. There was extensive degeneration of the nerve fibres; and, by the time the abnormal tissue had been resected, there was a large gap between the nerve ends, which precluded suture. Figure 2 depicts the operation findings. The opposite elbow was normal on radiographic examination. 
The operation findings were interpreted thus. At the time of the original injury the nerve must have been trapped in the elbow joint and also came to lie between the medial epicondyle and the rest of the humerus. In the course of time the medial epicondyle had joined to the

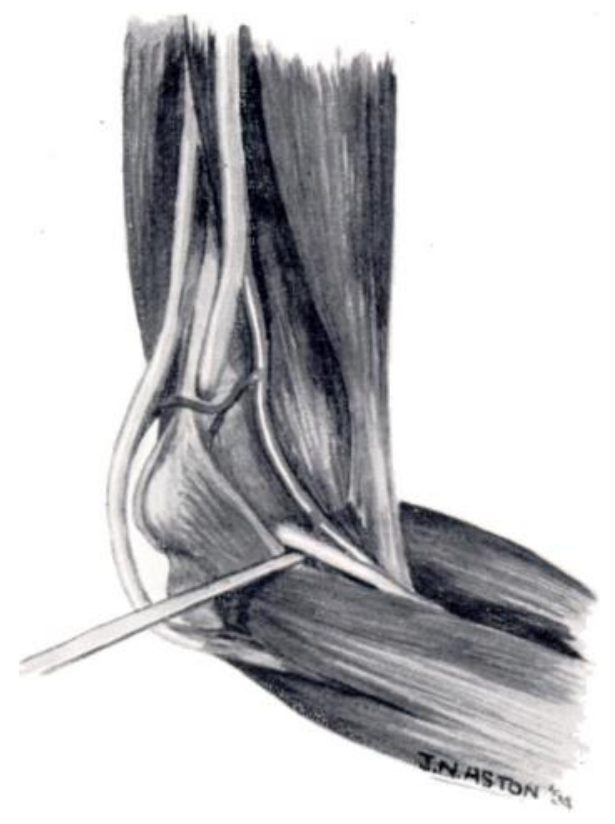

Fig. 2

Drawing of the conditions found at operation.

rest of the humerus. but the foramen had remained where the median nerve passed between the bone ends. It is uncertain whether the median nerve had been torn at the time of the original injury or whether continued pressure between the trochlea and the olecranon had divided it. 